\title{
Diagnostic Criteria and Treatment Modalities of Ectopic Pregnancies: A Literature Review
}

\author{
Authors: \\ *Ibrahim A. Abdelazim, ${ }^{1,2}$ Mohannad AbuFaza,, ${ }^{2}$ Svetlana Shikanova, ${ }^{3}$ \\ Bakyt Karimova ${ }^{3}$ \\ 1. Ain Shams University, Cairo, Egypt \\ 2. Ahmadi Hospital, Kuwait Oil Company (KOC), Ahmadi, Kuwait \\ 3. West Kazakhstan Medical University, Aktobe, Kazakhstan \\ *Correspondence to dr.ibrahimanwar@gmail.com
}

Disclosure: $\quad$ The authors have declared no conflicts of interest.

Received: $\quad 29.04 .20$

Accepted: $\quad 15.02 .21$

Keywords: Diagnostic, ectopic, modalities, pregnancies, treatment.

Citation:

EMJ Repro Health. 2021;7[1]:83-94.

\begin{abstract}
Background: Ruptured ectopic or extrauterine pregnancy (EP) is responsible for $6 \%$ of maternal deaths in the first trimester. This review was designed to summarise the diagnostic criteria and treatment modalities of EPs.

Methods: Recent guidelines of the international societies of obstetrics and gynaecology, including the Royal College of Obstetricians and Gynaecologists (RCOG), the American College of Obstetricians and Gynecologists (ACOG), and the European Society of Human Reproduction and Embryology (ESHRE), were reviewed to summarise the diagnostic criteria and treatment modalities of EPs.

Results: A minimum $\beta$-human chorionic gonadotropin ( $\beta$-hCG) rise of $\geq 35 \%$ in 48 hours was suggested to diagnose intrauterine pregnancy. A $\beta-$ hCG rise $<35 \%$ in 48 hours has $96.2 \%$ positive predictive value, $69.7 \%$ negative predictive value, and $80.2 \%$ overall accuracy in predicting EPs. The blob sign has $>90 \%$ positive predictive value in diagnosing EPs in symptomatic females with positive $\beta$-hCG and no definite intrauterine gestational sac by transvaginal sonography. The interstitial ectopic pregnancy and cornual pregnancy are two separate entities of EPs. Interstitial line sign has $80 \%$ sensitivity and $98 \%$ specificity in diagnosing interstitial ectopic pregnancy. A meta-analysis reported $89 \%$ overall success rate for methotrexate in treatment of EPs; the multi-dose regimen was significantly more successful than the single-dose regimen.
\end{abstract}

Conclusion: Institutes and healthcare providers should follow clear guidelines and/or protocols for the management of EPs. Institutes should implement competency-directed training programmes to increase healthcare providers' skills to diagnose and treat EP variants using different modalities.

\section{INTRODUCTION}

Ectopic or extrauterine pregnancy (EP) is a first trimester pregnancy complication that occurs in $1.3-2.4 \%$ of all pregnancies. ${ }^{1}$ Ruptured EP is

responsible for $6 \%$ of maternal deaths in the first trimester ${ }^{1,2}$ The increased rates of assisted reproductive techniques (ARTs), tubal surgeries, and improved diagnostic tools are responsible for increased incidence of EPs. 
A minimum $\beta$-human chorionic gonadotropin ( $\beta-h C G$ ) rise of $\geq 35 \%$ in 48 hours was suggested to diagnose intrauterine pregnancy (IUP). A $\beta$-hCG rise $<35 \%$ in 48 hours has $96.2 \%$ positive predictive value (PPV), 69.7\% negative predictive value, and $80.2 \%$ overall accuracy in predicting EPs. ${ }^{3}$ The blob sign has $>90 \%$ PPV in diagnosing EPs in symptomatic females with positive $\beta$-hCG and no definite intrauterine gestational sac (IUGS) by transvaginal sonography (TVS). ${ }^{2}$

The interstitial ectopic pregnancy (IEP) and cornual pregnancy are two separate entities of EPs. Interstitial line sign has $80 \%$ sensitivity and $98 \%$ specificity in diagnosing IEP.4-9

The American College of Obstetricians and Gynecologists (ACOG) reported spontaneous resolution of EPs in $88 \%$ of patients at initial $\beta$-hCG $<200 \mathrm{mlU} / \mathrm{mL}$ following expectant managment. ${ }^{10}$

A meta-analysis reported an $89 \%$ overall success rate for methotrexate (MTX) in treatment of EPs; the multi-dose regimen was significantly more successful than the single-dose regimen but caused more side effects." Despite the available diagnostic tools, delayed diagnosis and unreliable follow-up make ruptured EPs a daily practice in obstetrics and gynaecology. This literature review was designed to summarise the diagnostic criteria and treatment modalities of EPs.

\section{DIAGNOSTIC CRITERIA AND TREATMENT MODALITIES OF ECTOPIC PREGNANCIES}

EPs occur following implantation of the fertilised ovum outside the normal uterine cavity.

\section{Classification of Extrauterine Pregnancies}

> Tubal EPs. These constitute $>90 \%$ of EPs. In $80 \%$ of cases, tubal EPs occur in the ampullary region of the fallopian tube (FT). It may occur in other parts of the FT, including isthmus, fimbria, or the interstitial portion.

> Non-tubal EPs. These constitute $<10 \%$ of EPs and may be cervical, ovarian, intramural, or abdominal.

> Heterotopic pregnancies (HPs).

$>$ Caesarean section (CS) scar pregnancies (CSSP).

\section{Incidence of Extrauterine Pregnancies}

> Tubal EPs occur in 1.3-2.4\% of all pregnancies. ${ }^{1}$ IEPs account for $4 \%$ of EPs.

> Non-tubal EPs:

1. Cervical EPs occur in 1:2,000-1:18,000 pregnancies. The incidence of ovarian EP is $2 \%$ and is the most common type of non-tubal EP.12

2. Intramural EP (pregnancies within the myometrium) account for $1 \%$ of EPs. Abdominal pregnancy (AP) accounts for $1.3 \%$ of EPs. ${ }^{13}$

3. HPs occur in 1:4,000-1:30,000 in the general population.

4. CSSP incidence rate increased following the increased caesarean section rates, and occurs in 1:1,800-1:2,216 pregnancies. $^{2}$

Taran et al. ${ }^{1}$ explained the rising incidence of EPS by the increased rates of ARTs, tubal surgeries, and improved diagnostic tools. ${ }^{1}$ Perkins et al. ${ }^{14}$ reported that the incidence of EPs following ARTs has decreased over time but the risk of EP increased following multiple embryo transfers during ARTs. ${ }^{14}$ In addition, the ACOG reported the multiple embryo transfers and tubal factors of infertility as risk factors for EPs following ARTs. ${ }^{10}$ Ruptured EP is responsible for $6 \%$ of maternal deaths in the first trimester. ${ }^{1,2} \mathrm{~A}$ review of mortality in ART-associated EPs reported a mortality rate of 31.9 deaths per 100,000 pregnancies. ${ }^{15}$

\section{AETIOLOGY OF EXTRAUTERINE PREGNANCIES}

The FT is the site of oocyte fertilisation. The migration of the fertilised oocyte to the uterine cavity for implantation is mediated by the FT smooth muscles and cilia. FT inflammation and/or dysfunction are implicated in oocyte retention and subsequent EPs. ${ }^{2}$

\section{Risk Factors for Tubal Extrauterine Pregnancies}

Up to $50 \%$ of females diagnosed with EPs have no identifiable risk factors; however, several risk factors have been associated with EPs.' High-risk factors (odds ratio [OR]: $>4.0$ ) include prior tubal surgery, prior EP, sterilisation, and 
intrauterine device (IUD) users. ${ }^{1}$ Moderate risk factors (OR: >2.0) include infertility, current or prior pelvic inflammatory disease, smoking, and more than one sexual partner. ${ }^{1}$ Mild risk factors (OR: <2.0) include age $>40$ years. ${ }^{1}$ IUD use decreases the overall pregnancy rates and prevents intrauterine implantation, with subsequent higher incidence of EPs in females conceiving with an IUD in place compared to the general population."

\section{Risk Factors for Non-tubal Extrauterine Pregnancies}

Previous dilation and curettage are risk factors of cervical EPs. Myometrial injury during curettage, myomectomy, or CS is a risk factor for intramural EPs. Pelvic inflammatory disease, ARTs, and endometriosis are risk factors for APs. ${ }^{1}$

\section{Risk Factors for Caesarean Section Scar Pregnancies}

Although the European Society of Human Reproduction and Embryology (ESHRE) classified CSSP as one of the uterine EPs, ${ }^{15}$ other authors classify CSSP as an IUP because it may result in live offspring if not terminated. ${ }^{16}$ CSSPS occur following implantation of the fertilised oocyte over the previous CS or hysterotomy scars. ${ }^{16}$ The number of scars is not a risk factor for CSSP, but it occurs following elective CS, which is explained by the impaired healing of an unprepared lower uterine segment. ${ }^{2}$

\section{Clinical Presentation of Extrauterine Pregnancies}

The triad of secondary amenorrhoea, first trimester spotting, and pelvic pain may occur with EPs as well as intact IUPs and early miscarriages. Further suggestive manifestations of EPs include pain on movement of the cervix, acute abdominal pain radiating to the shoulder(s), abdominal guarding, hypovolaemic shock, and syncope. Differential diagnosis of EPs includes complicated ovarian or adnexal cyst, tubo-ovarian abscess, appendicitis, and ovarian hyperstimulation syndrome. ${ }^{1}$

\section{DIAGNOSIS OF EXTRAUTERINE PREGNANCIES}

\section{B-human Chorionic Gonadotropin}

Suspicion of an EP begins after a positive pregnancy test and with the absence of definite IUGS by ultrasound; i.e., pregnancy of unknown location (PUL). Definite IUGS means IUGS with yolk sac and/or embryo. ${ }^{1,13}$ The diagnosis of PUL will be changed to IUP in approximately $30 \%$ of cases after appearance of definite IUGS by ultrasound, while the majority of PUL (50-70\%) will be changed to either miscarriages or EPs. $\beta$-hCG is produced by the syncytiotrophoblasts, detected in the blood by the second week of pregnancy, and its measurement is crucial to clarify pregnancy location and prognosis. ${ }^{2}$ A single $\beta$-hCG assay is insufficient to detect early pregnancy prognosis, and serial $\beta-h C G$ are commonly used to monitor early pregnancies. ${ }^{3}$

The recommendations of $\beta$-hCG rise came from retrospective review of PUL, which suggested a minimum $\beta$-hCG rise of $\geq 35 \%$ in 48 hours to diagnose IUP. ${ }^{3}$ A $\beta$-hCG rise $<35 \%$ in 48 hours has $96.2 \%$ PPV, $69.7 \%$ negative predictive value, and $80.2 \%$ overall accuracy in predicting EPs. ${ }^{3}$ EPs are generally associated with a rise in $\beta-h C G$ by no more than $66 \%$, or a fall by no more than $13 \%$ from the baseline level, in 48 hours. The combination of $\beta-h C G$ ratio lying within this range, along with initial $\beta-\mathrm{hCG}>1,500 \mathrm{mlU} / \mathrm{mL}$ in the absence of definite IUGS, has $92 \%$ sensitivity and $84 \%$ specificity in predicting EPs. ${ }^{17}$

\section{Serum Progesterone}

A meta-analysis concluded that a serum progesterone level of $<10 \mathrm{ng} / \mathrm{mL}$ predicts non-viable pregnancy with $66.5 \%$ sensitivity and $96.3 \%$ specificity. ${ }^{18}$ Serum progesterone is not useful in predicting EPs and cannot differentiate EPs from early miscarriages. ${ }^{19}$

\section{Discriminatory Zone}

The discriminatory zone is the serum $\beta$-hCG level at which definite IUGS can be seen by the TVS, confirming the diagnosis of IUP $(\geq 1,000$ $2,000 \mathrm{mlU} / \mathrm{mL})^{2}$ Despite the discriminatory zone, a review of PUL reported visualisation of IUGS confirming the diagnosis of IUPS in nine females with $\beta$-hCG $>2,000 \mathrm{mIU} / \mathrm{mL} .{ }^{20}$ In multiple 
pregnancies, definite IUGS(s) may be seen at $\beta$-hCG value higher than the discriminatory zone identified for singleton IUP. ${ }^{2}$

A positive pregnancy test in the absence of definite IUGS should be considered EP until proven otherwise. The risk of EP is much reduced (but not zero) after visualisation of IUGS because of the possibility of HP. ${ }^{2}$

\section{Additional Ultrasound Findings}

Additional ultrasound findings may be useful to increase the suspicion for EPs. IUPs have significantly higher endometrial thickness than miscarriages or EPs $(17 \mathrm{~mm}$ versus $12 \mathrm{~mm}$, respectively). ${ }^{21}$ In $20 \%$ of tubal EPs, a collection of fluid within the uterine cavity could be seen, referred to as the pseudosac (pseudosac is not diagnostic for tubal EPs). ${ }^{21} \mathrm{~A}$ small amount of fluid in the Pouch of Douglas may be found in both IUPs and EPs, while large amounts of free fluid, particularly in the Morrison's pouch, may indicate haemoperitoneum in ruptured EPs. ${ }^{2}$ Visualisation of an adnexal gestational sac (GS) with yolk sac and/or embryo as an echogenic periphery and non-echogenic interior (bagel sign) with circumferential Doppler flow without definite IUGS is highly suggestive of EP.' If the visualised, suspicious GS is round, echogenic, and moves separately from the ovary, this is considered the 'blob sign'. The blob sign has $>90 \%$ PPV in diagnosing EPs in symptomatic females with positive $\beta$-hCG and no definite IUGS by TVS. ${ }^{2}$

A systematic review concluded that $88 \%$ of tubal EPs were diagnosed by the combination of an absent IUGS with an adnexal mass. ${ }^{2}$ Ultrasound criteria of IEPs occur following implantation of the fertilised oocytes in the interstitial portion of the FT when it traverses through the uterine muscular wall $(1-2 \mathrm{~cm})$ to enter the cavity, and is a separate entity from the cornual pregnancy. Cornual pregnancy describes pregnancy in the rudimentary horn of a uterus with Müllerian anomaly. ${ }^{4-9}$ The ultrasound criteria of the IEPS include an empty uterus with an eccentric GS seen separate from the endometrium, and the GS $>1 \mathrm{~cm}$ away from the most lateral edge of the uterine cavity and surrounded by $<5 \mathrm{~mm}$ myometrium in all imaging planes. Interstitial line sign has $80 \%$ sensitivity and $98 \%$ specificity in diagnosing IEPs. Interstitial line sign is an echogenic line extending from the GS to the endometrium cavity, representing the interstitial portion of the FT. ${ }^{4-9}$

In the absence of definite IUGS, non-tubal EPS can be suspected by specific ultrasound criteria. Cervical EPs can be identified by an empty uterus, a soft and ballooned cervix (barrelshaped cervix), the GS lying within the cervical canal below the closed internal cervical os with evident blood flow around the GS detected by the colour Doppler, or absence of the sliding sign. ${ }^{13,23}$ The sliding sign is used to differentiate the cervical EPs from miscarriages within the cervical canal. When pressure is applied on the cervix by the transvaginal probe, the GS slides against the endocervical canal in miscarriage but it does not in cervical EPs. ${ }^{13,23}$

There are no specific ultrasound criteria for the ovarian EPs. ${ }^{12}$ Ovarian EPs are suspected by an empty uterus, a wide echogenic ring with internal anechoic area seen in the ovary, evident blood flow surrounding the echogenic ring detected by colour Doppler, and ovarian EP movement with the movement of the ovary when pressure is applied by the transvaginal probe. ${ }^{2}$ Ruptured ovarian EP could be seen by ultrasound as a complex adnexal mass with free fluid in the Pouch of Douglas. ${ }^{12}$ It may be difficult to differentiate an ovarian EP from an ovarian cyst, and definite diagnosis can be confirmed at laparoscopy. ${ }^{24}$

AP can be either primary, following implantation of the fertilised oocyte into the peritoneal surface (rare), or secondary, following ruptured tubal EP or tubal abortion. The ultrasound suggestive criteria of APs include an empty uterus, lack of evidence of dilated FT or complex adnexal mass, a gestational cavity proximal to the anterior abdominal wall and surrounded by bowel loops, and no myometrium separating the gestational cavity from the urinary bladder. ${ }^{25}$

The diagnosis for primary AP diagnosed with laparotomy using the Studdiford's Criteria includes healthy tubes and ovaries with no evidence of recent or remote injury, no evidence of utero-placental fistula, and recent pregnancy related exclusively to the peritoneal surface. ${ }^{26}$

Ultrasound criteria of CSSPs include an empty uterus with an empty, closed endo-cervical canal, location of the GS in the lower anterior quadrant of the uterus below the bladder close to the internal cervical os and previous scar(s) 
with yolk sac and/or embryo, a thin myometrial layer between the GS and urinary bladder, and numerous blood vessels and arterio-venous malformation around the GS. ${ }^{16}$

Laparoscopy is the gold standard for surgical treatment of EPs. Its role in diagnosing EPs decreased after the use of TVS and $\beta-h C G .{ }^{14}$

\section{TREATMENT OF TUBAL EXTRAUTERINE PREGNANCY}

\section{Expectant Management}

The ACOG reported spontaneous resolution of EPs in $88 \%$ of patients at initial $\beta-h C G<200$ $\mathrm{mlU} / \mathrm{ml}$ following expectant management. ${ }^{10}$ In addition, a retrospective study, reported $88 \%$ success rate following expectant management for EPs at initial $\beta-h C G<200 \mathrm{mlU} / \mathrm{ml}$, while the success rate was $25 \%$ success rate at initial $\beta-h C G$ $>2,000 \mathrm{mlU} / \mathrm{I}^{27}$ (Table 1). The Royal College of Obstetricians and Gynaecologists (RCOG) recommends expectant management for tubal EPs at initial $\beta$-hCG $<1,500 \mathrm{mlU} / \mathrm{mL}$ in clinically stable patients with decreasing $\beta$-hCG. ${ }^{13}$

\section{Medical Treatment}

Medical treatment of EPs using MTX is more costeffective than surgical treatment, with similar success rates ${ }^{29}$ (Tables 1 and 2 ).

\section{Systemic methotrexate regimens}

A systematic review showed that the success rate of single-dose MTX was $94.4 \%$ when the initial $\beta$-hCG was between 1,000 and $1,999 \mathrm{mlU} / \mathrm{mL}$, and was $81.1 \%$ when the initial $\beta$-hCG was between 10,000 and 150,000 mlU/mL.30 Two-dose MTX regimen has been proposed by Barnhart et al. ${ }^{31}$ with $87 \%$ success rate. A retrospective study reported $87 \%$ success rate for the single-dose MTX regimen at initial $\beta$-hCG of $4,801 \mathrm{mlU} / \mathrm{mL}$ versus $90 \%$ success rate for the two-dose MTX regimen at initial $\beta$-hCG of $4,278 \mathrm{mlU} / \mathrm{mL}^{32}$

A meta-analysis reported $89 \%$ overall success rate for multiple-dose MTX in treatment of EPs; the multi-dose regimen was significantly more successful than the single-dose regimen (93\% versus $88 \%$ ) but caused more side effects. ${ }^{11}$

\section{Surgical Treatment}

Laparoscopy is the gold standard for surgical treatment of EPs for fast recovery, minimal hospital stays, and cost.,2 The surgical methods used for treatment of tubal EPs are salpingectomy or salpingostomy (Table 1). ${ }^{28}$ The decision of salpingectomy or salpingostomy depends on the contralateral FT status and desired future fertility. ${ }^{14}$

\section{TREATMENT OF INTERSTITIAL ECTOPIC PREGNANCY}

Treatment of IEPS is reliant on gestational age at diagnosis, whether the IEP is intact or ruptured, and desired future fertility. The non-surgical options can be used with intact IEP, while a ruptured IEP is a medical emergency that requires surgery.

\section{Non-surgical Treatment}

Non-surgical treatment includes expectant management, systemic MTX, and local injections $^{33,34}$ (Table 3). The risks of non-surgical treatment for IEPs include subsequent rupture and life-threatening haemorrhage.

\section{Surgical Treatment}

Surgical treatment is indicated with ruptured IEPs and when non-surgical treatment fails or is not feasible. Laparotomy has previously been the traditional route for surgical treatment of IEPs, particularly ruptured IEPs. Laparoscopic approach is now commonly used for surgical treatment of intact or even ruptured IEPs $^{33}$ (Table 3).

\section{TREATMENT OF NON-TUBAL ECTOPIC PREGNANCY}

\section{Cervical Ectopic Pregnancy}

Cervical EPs may be managed medically, surgically, or by combined approaches. The use of systemic and/or local MTX has been described in case reports of cervical EPs. ${ }^{35}$ An $87 \%$ success rate was reported in a series of cervical EPs treated with local MTX and additional potassium chloride injections. ${ }^{36}$ 
Table 1: Treatment of tubal ectopic pregnancies.

\begin{tabular}{|c|c|}
\hline \multirow[t]{3}{*}{$\begin{array}{l}\text { Expectant } \\
\text { management }\end{array}$} & $\begin{array}{l}\text { ACOG: } \\
\text { - } \quad \text { Asymptomatic and reliable patients for follow-up } \\
\text { - } \quad \text { Low } \beta-h C G ~ 175-200 \mathrm{mlU} / \mathrm{mL} \\
\text { - } \quad \text { Haemodynamically stable (no evidence of ruptured } E P)^{10}\end{array}$ \\
\hline & $\begin{array}{l}\text { RCOG: } \\
\text { - Expectant management for tubal EPs at initial } \beta-\mathrm{hCG}<1,500 \mathrm{mIU} / \mathrm{mL} \text { after ultrasound } \\
\text { diagnosis in a clinically stable patient } \mathrm{t}^{13}\end{array}$ \\
\hline & - $\quad$ Decreased $\beta-h C G$ within 48 hours indicates successful expectant management \\
\hline \multirow[t]{5}{*}{$\begin{array}{l}\text { Medical MTX } \\
\text { treatment }\end{array}$} & $\begin{array}{l}\text { - MTX is a dihydrofolate reductase inhibitor that disrupts DNA and RNA synthesis, and targets } \\
\text { the rapidly dividing trophoblasts }{ }^{10} \\
\text { The most common side effects of MTX are elevated liver enzymes (mild and transient), } \\
\text { nausea, abdominal pain, dermatitis, and stomatitis } \\
\text { - Females should be advised to cease alcohol consumption (which elevates liver enzymes) } \\
\text { and folate supplementation (which counteracts MTX action) before MTX treatment }\end{array}$ \\
\hline & $\begin{array}{l}\text { Indication of MTX: } \\
\text { - } \quad \text { Haemodynamically stable and reliable patient for follow-up } \\
\text { - } \quad \text { Pre-treatment } \beta-h C G ~ 1,500-5,000 \mathrm{mlU} / \mathrm{mL} \\
\text { - } \quad \text { Ectopic size <4 cm in largest diameter } \\
\text { - } \quad \text { No fetal cardiac activity } \\
\text { - } \quad \text { No concomitant IUP } \\
\text { - } \quad \text { No known sensitivity to MTX }\end{array}$ \\
\hline & $\begin{array}{l}\text { Before MTX therapy: } \\
\text { - A blood sample for } \beta-h C G \text { assay, CBC, liver, and kidney functions tests should be taken. } \\
\text { - A chest X-ray should be considered to exclude active pulmonary lesions, and Rh status to } \\
\text { determine females in need for Rho(D) Ig } \\
\text { - TVS to obtain the baseline ultrasound criteria of the EP and exclude concomitant IUP10 }\end{array}$ \\
\hline & 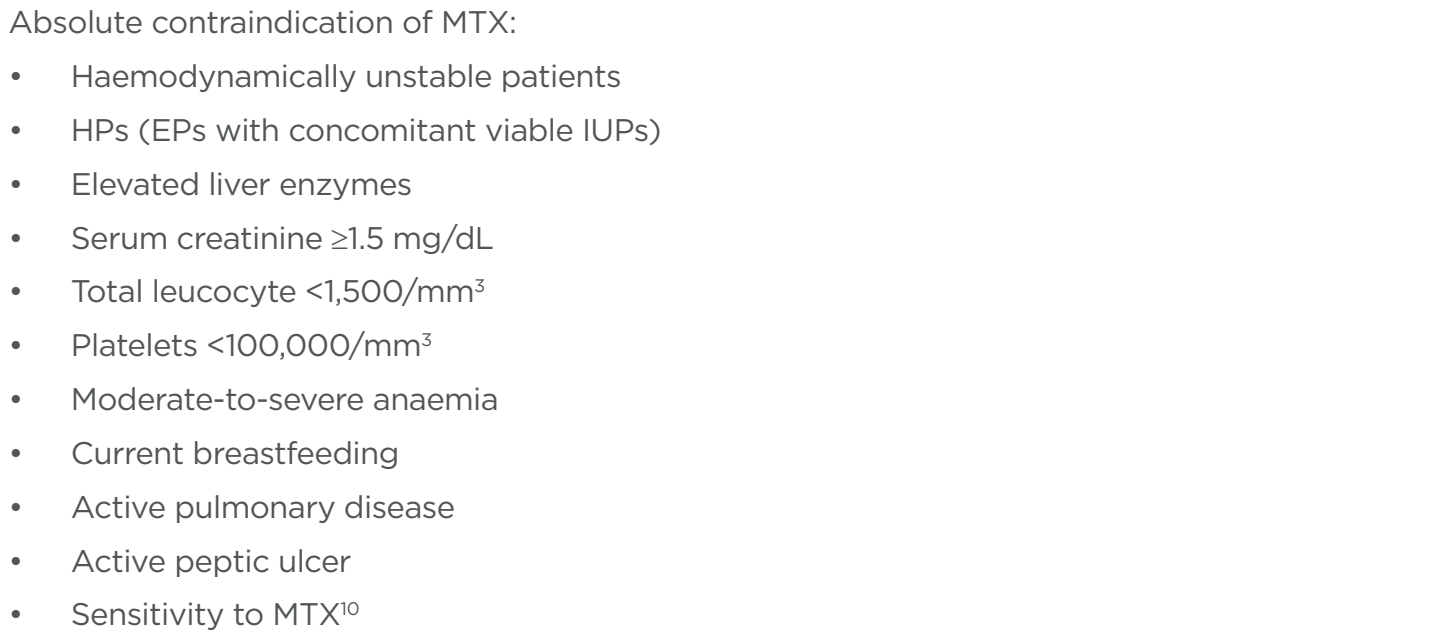 \\
\hline & $\begin{array}{l}\text { Relative contraindication of MTX: } \\
\text { - } \quad \text { Presence of fetal cardiac activity } \\
\text { - } \quad \text { B-hCG level }>5,000 \mathrm{mIU} / \mathrm{mL} \\
\text { - } \quad \text { An ectopic mass size }>4 \mathrm{~cm} \text { in largest diameter } \\
\text { - } \quad \text { Unreliable patient for follow-up }{ }^{10}\end{array}$ \\
\hline
\end{tabular}




\begin{tabular}{|c|c|}
\hline \multirow[t]{3}{*}{ Surgical treatment } & $\begin{array}{l}\text { Indications: } \\
\text { - Surgical management for EPs is indicated when the medical treatment fails or is } \\
\text { contraindicated, or when ruptured EP is suspected }\end{array}$ \\
\hline & $\begin{array}{l}\text { Salpingectomy (removal of the FT): }{ }^{28} \\
\text { - } \quad \text { Recommended in cases of extensive tubal damage, rupture, prior tubal sterilisation, or a } \\
\text { large tubal EP }(>5 \mathrm{~cm} \text { in diameter) } \\
\text { - } \quad \text { If the final histological examination of the FT after salpingectomy demonstrates evidence of } \\
\text { a tubal gestation, no further assessment or follow-up } \beta-h C G \text { needed } \\
\text { - } \quad \text { PTT is more common after salpingostomy }(7 \%) \text { compared to salpingectomy }(<1 \%) \text {. }\end{array}$ \\
\hline & $\begin{array}{l}\text { Salpingostomy (removal of the EP through a tubal incision): } 28 \\
\text { - } 1-2 \mathrm{~cm} \text { linear incision made with electrocautery or scalpel over the bulging EP, the contents } \\
\text { of the EP removed using forceps or hydro-dissection (hydro-dissection preferred to avoid } \\
\text { incomplete removal and PTT) } \\
\text { - The tubal incision can be left open to heal by secondary intention or sutured closed; a } \\
\text { Cochrane review reported an insignificant difference between the two techniques regarding } \\
\text { the rates of EP recurrence and subsequent IUP28 } \\
\text { - After salpingostomy, weekly } \beta \text {-hCG assay is necessary to rule out PTT } \\
\text { - Single dose of MTX 24-hours post-operatively was reported to decrease the rate of PTT } \\
\text { after salpingostomy }\end{array}$ \\
\hline
\end{tabular}

ACOG: American College of Obstetricians and Gynecologists; $\beta$-hCG: $\beta$-human chorionic gonadotropin; CBC: complete blood count; EP: ectopic pregnancy; FT: fallopian tube; HP: heterotropic pregnancy; IUP: intrauterine pregnancy; MTX: methotrexate; PTT: persistent trophoblastic tissue; RCOG: Royal College of Obstetricians and Gynaecologists; Rh: rhesus; TVS: transvaginal sonography.

A success rate of $61.5 \%$ was reported in a series of cervical EPs treated with systemic MTX. ${ }^{37}$ Gestational age $>9$ weeks, $\beta-h C G>10,000 \mathrm{mlU} /$ $\mathrm{mL}$, positive fetal cardiac activity, and crownrump length $>10 \mathrm{~mm}$ were associated with high failure rates of MTX in treatment of cervical EPs. ${ }^{13}$

Dilation and curettage is not recommended as first-line treatment because of bleeding risks (40\% hysterectomy rate reported following dilation and curettage for cervical EPs). ${ }^{2}$ Placement of cervical sutures, intracervical balloon tamponade, and/or pre-operative feticide injection were reported to minimise the bleeding risks during the management of cervical EPs. ${ }^{38}$ Uterine artery embolisation has been reported as a prophylactic measure prior to cervical EP treatment or as an emergency treatment. ${ }^{39}$

\section{Ovarian Ectopic Pregnancy Treatment}

Ovarian EP treatment is primarily surgical, and laparoscopy is the gold standard for haemodynamically stable ovarian EPs. ${ }^{12,13}$
Resection of the ovarian EP and conservative ovarian surgery are usually the main surgical objectives, particularly in females desiring future fertility.

Successful treatment of ovarian EPs using systemic MTX at initial $\beta$-hCG up to $5,201 \mathrm{mIU} / \mathrm{mL}$, as well as local MTX injection at initial $\beta-h C G$ up to $12,075 \mathrm{mlU} / \mathrm{mL}$, has been reported. ${ }^{40,41}$

\section{Intramural Ectopic Pregnancy Treatment}

Intramural EP treatment is dependent on the patient's condition at the time of diagnosis. Reported cases of intramural EPs in the literature have been managed surgically and sometimes with hysterectomy following ruptured intramural EP. ${ }^{2}$ Recent reports described the laparoscopic treatment of intramural EPs. ${ }^{42}$ In clinically stable patients, medical treatment of intramural EPs using systemic MTX was successful even with high $\beta$-hCG up to $25,140 \mathrm{mlU} / \mathrm{mL}^{43}$ Successful 
management of intramural EPs using local MTX, potassium chloride injections at initial $\beta$-hCG of $74,872 \mathrm{mlU} / \mathrm{mL},{ }^{44}$ as well as uterine artery embolisation at initial $\beta-h C G$ level of $12,250 \mathrm{mlU} / \mathrm{mL},{ }^{45}$ have been reported.

\section{Abdominal Pregnancy Treatment}

Advanced APs should be managed by laparotomy and a multi-disciplinary team. ${ }^{26}$ After delivery of the fetus, the placenta should be left in situ if attached by major vessels or vital structures, followed by multi-dose systemic MTX, antibiotics, and follow-up. Attempts to remove the placenta may precipitate severe haemorrhage. ${ }^{26}$ Preoperative MRI defines the placental implantation site. ${ }^{26}$ Intra-operative massive bleeding from the placental site can be controlled by interlocking sutures and/or packing. Packing and/or retained in situ placenta associated with risks of ileus, peritonitis, and abscess formation may necessitate a second-look laparotomy. ${ }^{26} \mathrm{~A}$ meta- analysis reported high rates of blood transfusion with hepatic (46\%) and retroperitoneal (40\%) APs. ${ }^{46}$

\section{TREATMENT OF HETEROTOPIC PREGNANCIES}

A review of the literature showed that most HPs (72.5\%) occur in the FT, while seven cases were cervical and three cases were CSSPs. ${ }^{47}$

\section{Tubal Heterotopic Pregnancies}

Medical treatments of tubal HPs include local potassium chloride or hyperosmolar glucose injections. More than $50 \%$ of the tubal HPs managed with local potassium chloride injections require subsequent salpingectomy. 48 Treatment of HPs with local and/or systemic MTX is contraindicated in the presence of viable IUP. ${ }^{2,13}$ Surgical management has been described more frequently with tubal HPs because most of the cases presented with tubal rupture. ${ }^{49}$

Table 2: Systemic methotrexate regimens.

\begin{tabular}{|c|c|}
\hline $\begin{array}{l}\text { Single-dose MTX } \\
\text { regimen } \\
\text { Menon S et al., }{ }^{30} \\
2007\end{array}$ & $\begin{array}{ll} & 50 \mathrm{mg} / \mathrm{m}^{2} \mathrm{MTX} \text {, IM injection } \\
\text { - } & \beta \text {-hCG level should be checked on Days } 4 \text { and } 7 \text { following MTX dose } \\
\text { - } & \text { Decreased } \beta \text {-hCG by } \geq 15 \% \text { on Day } 7 \text { indicates successful MTX treatment } \\
\text { - } & \text { Increased } \beta-h C G \text { level or }<15 \% \text { drop on Day } 7 \text { indicates second dose MTX needed } \\
\text { - } & \text { The success rates of MTX in treatment of EPs are high with low initial } \beta-h C G \text { levels }\end{array}$ \\
\hline $\begin{array}{l}\text { Two-dose MTX } \\
\text { regimen } \\
\text { Barnhart KT et al., }{ }^{31} \\
2007\end{array}$ & $\begin{array}{l}\text { - Two-dose MTX regimen has been proposed by Barnhart et al., with } 87 \% \text { success rate and } \\
\text { minimal side effects }{ }^{31} \\
\text { - A retrospective study reported } 87 \% \text { success rate for the single-dose MTX regimen in } \\
\text { treatment of EPs at initial } \beta-h C G \text { of } 4,801 \mathrm{mlU} / \mathrm{mL} \text { versus } 90 \% \text { success rate for the two-dose } \\
\text { MTX regimen at initial } \beta-\mathrm{hCG} \text { of } 4,278 \mathrm{mIU} / \mathrm{mL}^{32}\end{array}$ \\
\hline $\begin{array}{l}\text { Multiple-dose MTX } \\
\text { regimen } \\
\text { Barnhart KT et al.,"1 } \\
2003\end{array}$ & $\begin{array}{l}\text { - The multiple-dose MTX regimen derived from the use of MTX in treatment of GTDs, } \\
\text { alternating with leucovorin (folinic acid to counteract the MTX side effects) } \\
\text { - MTX ( } 1 \mathrm{mg} / \mathrm{kg} \text { body weight) on Days } 0,2,4 \text {, and } 6 \text { alternating with leucovorin (folinic acid } \\
0.1 \mathrm{mg} / \mathrm{kg} \text { ) on Days } 1,3,5 \text {, and } 7 \text { combined with follow-up by } \beta-\mathrm{hCG} \text { until the } \beta \text {-hCG falls by } \\
>15 \% \text { from its peak value } \\
\text { - } \quad \text { Regardless of which MTX regimen used, if the } \beta-\mathrm{hCG} \text { level does not decline adequately } \\
\text { (<15\% on Day } 7 \text { ) or increases, surgical management should be considered } \\
\text { - If a patient's serum } \beta-h C G \text { declines adequately ( } \geq 15 \% \text { on Day } 7 \text { ), no further intervention is } \\
\text { required and the } \beta-h C G \text { level should be monitored weekly until it reaches non-pregnant level } \\
\text { - } \beta-h C G \text { usually returns to normal (non-pregnant) level within } 2-3 \text { weeks }\end{array}$ \\
\hline
\end{tabular}

ß-hCG: $\beta$-human chorionic gonadotropin; GTD: gestational trophoblastic disease; IM: intramuscular; MTX: methotrexate. 
Table 3: Treatment of interstitial ectopic pregnancies.

\begin{tabular}{|c|c|}
\hline \multicolumn{2}{|c|}{ Non-surgical treatment } \\
\hline $\begin{array}{l}\text { Expectant } \\
\text { management }\end{array}$ & - $\quad$ Appropriate for asymptomatic IEPs with low and/or decreasing $\beta$-hCG 33,34 \\
\hline Systemic MTX & $\begin{array}{l}\text { - The success rate of systemic MTX in treatment of IEPs was } 80 \% \text { even with high } \beta \text {-hCG levels } \\
\text { (106,634 } \mathrm{mIU} / \mathrm{mL} \text { ) and presence of fetal cardiac activity } \\
\text { - Surgery for ruptured IEP or rising } \beta-\mathrm{hCG} \text { may be required for } 10-20 \% \text { of IEPs treated with } \\
\text { systemic MTX } \\
\text { - Close follow-up is necessary, and hospitalisation is rarely needed except for females with } \\
\text { uncertain diagnosis } \\
\text { - Many studies support the multi-dose systemic MTX regimen for treatment of IEPs }\end{array}$ \\
\hline Local injections & $\begin{array}{l}\text { - MTX (most common), while } 20 \% \text { potassium chloride is preferred in IEPs associated with } \\
\text { concomitant viable IUPS } \\
\text { - Injection can be carried out via laparoscopic, hysteroscopic, or ultrasound-guided techniques } \\
\text { - The success rate of local MTX in treatment of IEPs was } 91 \% \text { in one case series and } 100 \% \text { in } \\
\text { other cases series } 33,34\end{array}$ \\
\hline \multicolumn{2}{|l|}{ Surgical treatment } \\
\hline $\begin{array}{l}\text { Transcervical } \\
\text { suction evacuation }\end{array}$ & $\begin{array}{l}\text { - Under laparoscopic or ultrasound guidance } \\
\text { Although this technique minimises the risk of uterine perforation at the cornua, there is } \\
\text { minimal data about the effect of this technique on the tensile strength of the cornua, tubal } \\
\text { patency, and future fertility }{ }^{33}\end{array}$ \\
\hline $\begin{array}{l}\text { Cornuostomy/ } \\
\text { salpingostomy } \\
\text { (can be done when } \\
\text { the IEP } \leq 4 \mathrm{~cm} \text { in } \\
\text { diameter) }\end{array}$ & $\begin{array}{l}\text { - Cornuostomy is equivalent to the linear salpingostomy technique that is used for surgical } \\
\text { treatment of tubal EPs } \\
\text { - The pregnancy is removed without removing the surrounding myometrium and the defect is } \\
\text { closed after achieving haemostasis } \\
\text { - Salpingostomy is a variation of the cornuostomy in which the incision is made at the insertion } \\
\text { point of the FT into the uterine fundus, which allows removal of the trophoblastic tissue } \\
\text { through this defect (done when the IEP diagnosed at early gestation) } \\
\text {-33 }\end{array}$ \\
\hline $\begin{array}{l}\text { Cornual resection } \\
\text { ([excision] can be } \\
\text { completed when } \\
\text { the IEPs }>4 \mathrm{~cm} \text { in } \\
\text { diameter) }\end{array}$ & $\begin{array}{l}\text { - The IEP and the surrounding uterine cornua are excised en-bloc through a circumferential } \\
\text { incision followed by suture closure of the myometrium after achieving haemostasis } \\
\text { - Diluted vasopressin can be injected into the myometrium around the IEP to minimise the } \\
\text { blood loss during surgery }{ }^{33}\end{array}$ \\
\hline $\begin{array}{l}\text { Cornual wedge } \\
\text { resection }\end{array}$ & $\begin{array}{l}\text { - Cornual wedge resection by laparotomy was the standard surgical treatment for IEPs before } \\
\text { laparoscopy } \\
\text { - Cornual wedge resection involves en-bloc removal of IEP, and the surrounding myometrium }\end{array}$ \\
\hline $\begin{array}{l}\text { Mini-cornual } \\
\text { excision }\end{array}$ & $\begin{array}{l}\text { - Described by Moawad et al. }{ }^{33} \text { as an elliptical incision along the long axis of the IEP in the } \\
\text { thinned-out myometrium through which the IEP is evacuated to preserve the architecture and } \\
\text { vascularity of the uterus } \\
\text { - The IEP base was intact, sometimes cauterisation is needed to achieve haemostasis } \\
\text { - No myometrial defect was noted, and no sutures were needed }{ }^{33}\end{array}$ \\
\hline Hysterectomy & $\begin{array}{l}\text { - Previously the standard of care to treat } 50 \% \text { of IEPs } \\
\text { It is not commonly used nowadays as a treatment option for IEPs except in cases complicated } \\
\text { with life-threatening haemorrhage }\end{array}$ \\
\hline
\end{tabular}

ß-hCG: $\beta$-human chorionic gonadotropin; EP: ectopic pregnancy; FT: fallopian tube; IEP: interstitial ectopic pregnancy; IUP: intrauterine pregnancy; MTX: methotrexate. 
Salpingectomy is preferable to salpingostomy in tubal HPs because the persistent trophoblastic tissue cannot be monitored in presence of ongoing IUP. ${ }^{2}$

Expectant management, hyperosmolar glucose injections, and cornual resection have been reported for management of interstitial HPs with successful live births..$^{50}$

\section{Non-tubal Heterotopic Pregnancies}

Expectant management, local injections (potassium chloride or hyperosmolar glucose), suction curettage, or hysteroscopic resection have been reported for management of cervical HPs with successful live birth. A live birth rate of $80 \%$ was reported in a series of cervical HPs for which cervical cerclage was used to minimise the bleeding after the intervention. ${ }^{51}$

At the time of writing, three cases of live births have been reported after local potassium chloride injection in APs. ${ }^{52}$ Local hyperosmolar glucose injection and laparoscopic wedge resection were reported for treatment of ovarian HPs with successful live birth. ${ }^{53}$ Surgical intervention of ovarian HPs carries the risk of interrupting the hormonal support for the co-existing IUP from the corpus luteum.

\section{TREATMENT OF CAESAREAN SECTION SCAR PREGNANCIES}

CSSP is a type of IUP, and it may result in a live offspring if not terminated. ${ }^{16}$ To date, there have been 27 live births reported following conservative management of CSSPs. ${ }^{13}$ For CSSPs with no yolk sac, and/or fetal cardiac activity, the ultrasound and biochemical follow-up are sufficient until the serum $\beta$-hCG returns to non-pregnant levels with or without MTX. ${ }^{16}$ For CSSPs with yolk sac and/or fetal cardiac activity, there are two treatment options: termination or continuation of the CSSP. Females who decide to continue the pregnancy should be counselled regarding the risks of haemorrhage, uterine rupture, morbid adherent placenta, and emergency hysterectomy. ${ }^{16}$ To date, there have been 22 emergency hysterectomies reported for lifethreatening haemorrhage and morbid adherent placenta following CSSPs. ${ }^{13}$

\section{Termination of Caesarean Section Scar Pregnancies}

Termination of CSSPs should be individualised based on the patient's age, desired future fertility, and clinician's experience.

\section{Surgical approaches}

Suction aspiration is the traditional choice for surgical approach but it exposes vessels to injury and is associated with major bleeding that may necessitate life-saving hysterectomy. Insertion of a Foley's catheter at the CSSP site, inflated with saline as compression tamponade, is a potentially useful approach, which can be combined with ultrasound-guided suction aspiration. ${ }^{16}$ Traditional dilation and curettage is often complicated by haemorrhage (76\% required further treatment, and $14 \%$ required hysterectomy in a series of CSSPS). ${ }^{54}$

Hysteroscopic bipolar resection has been reported for CSSP management at initial $\beta$-hCG up to $28,333 \mathrm{mIU} / \mathrm{mL} .{ }^{55}$ Hysteroscopic resection is not preferred for CSSP management when the residual myometrium is $<3 \mathrm{~mm}$ because of uterine perforation and bladder injury risks. Trans-abdominal excision of CSSPs (laparotomy or laparoscopy) allows revision of the lower uterine segment and reduces recurrence risks. Laparotomy is indicated in CSSPs if complicated by life-threatening haemorrhage or suspected uterine rupture.

\section{Local injections}

Ultrasound-guided local MTX or potassium chloride injection is the most effective treatment for CSSPs between 6 and 8 weeks; it stops the cardiac activity immediately and should be considered when future fertility desired. ${ }^{16}$

\section{Systemic Methotrexate Regimens}

Several authors have supported the multi-dose systemic MTX regimen for CSSP treatment combined with ultrasound and $\beta$-hCG followup until the $\beta$-hCG returns to non-pregnant levels. Persistent trophoblastic tissue may occur following medical and/or surgical treatments of CSSPs except for hysterectomy. ${ }^{16}$ 


\section{Recurrence of \\ Extrauterine Pregnancies}

The recurrence of EPs is not affected by the treatment modality. The ESEP trial showed that the EP recurrence was similar following salpingostomy or salpingectomy (8\% and $5 \%$, respectively). ${ }^{56}$ The reported recurrence rate following prior IEPs was $9.4 \% .^{57}$ One case of recurrent cervical EP reported in a series of cervical EPs was treated with different modalities. ${ }^{58}$ The data are insufficient to comment on the recurrence rates following prior ovarian, intramural EPs, or APs.
Conception is not recommended for 3 months after MTX therapy. IUP rates are similar with no significant difference following salpingostomy or salpingectomy in the ESEP and DEMETER trials. ${ }^{56,59}$ In addition to this, IUP rates within 2 years after prior tubal EP were similar among salpingectomy (67\%), salpingostomy (76\%), and medical treatment (76\%) in a populationbased study. ${ }^{60}$ Institutes and healthcare providers should follow clear guidelines and protocols for management of EPs. Institutes should implement competency-directed training programmes to increase healthcare providers' skills to diagnose and treat EP variants using different modalities.

\section{References}

1. Taran FA et al. The diagnosis and treatment of ectopic pregnancy. Dtsch Arztebl Int. 2015;112(41):693704.

2. Panelli DM et al. Incidence, diagnosis, and management of tubal and nontubal ectopic pregnancies: a review. Fertil Res Pract. 2015;1:15.

3. Morse $\mathrm{CB}$ et al. Performance of human chorionic gonadotropin curves in women at risk for ectopic pregnancy: exceptions to the rules. Fertil Steril. 2012;97(1):101-6.e2.

4. Kanshaiym $S$ et al. Successful procedure in conservative management of interstitial (cornual) ectopic pregnancy. Gynecol Minim Invasive Ther. 2019;8(3):140-1.

5. Xu W, Zhang S. Reply letter to: "comments on manuscript: laparoscopic treatment of cornual heterotopic pregnancy: a retrospective cohort study". Int J Surg. 2019;68:168-9.

6. Abdelazim IA et al. Comments on manuscript: interstitial and cornual ectopic pregnancy: conservative surgical and medical management. J Obstet Gynaecol India. 2019;69(5):476-7.

7. Abdelazim IA et al. Regarding "spontaneous cornual pregnancy after homolateral salpingectomy for an earlier tubal pregnancy: a case report and literature review". J Minim Invasive Gynecol. 2019;26(3):574-5.

8. Abdelazim IA et al. Regarding "laparoscopic management 4 cases of recurrent cornual ectopic pregnancy and review of literature,". J Minim Invasive Gynecol.
2019;26(4):774.

9. Abdelazim IA et al. Regarding "technique for the laparoscopic management of a cornual ectopic pregnancy". J Minim Invasive Gynecol. 2019;26(4):777-8.

10. Committee on Practice BulletinsGynecology. ACOG practice bulletin no. 191: tubal ectopic pregnancy. Obstet Gynecol. 2018;131(2):e65-77.

11. Barnhart KT et al. The medical management of ectopic pregnancy: a meta-analysis comparing "single dose" and "multidose" regimens. Obstet Gynecol. 2003;101(4):778-84.

12. Begum $\mathrm{J}$ et al. Diagnostic dilemma in ovarian pregnancy: a case series. J Clin Diagn Res. 2015;9(4):QR01-3.

13. Elson $\mathrm{CJ}$ et al. Diagnosis and management of ectopic pregnancy. Erratum in: BJOG. 2016;123(13):e15-55

14. Perkins KM et al. Risk of ectopic pregnancy associated with assisted reproductive technology in the United States, 2001-2011. Obstet Gynecol. 2015;125(1):70-8.

15. Kirk E et al.; ESHRE working group on Ectopic Pregnancy. Terminology for describing normally sited and ectopic pregnancies on ultrasound: ESHRE recommendations for good practice. Hum Reprod Open. 2020;2020(4):hoaa055.

16. Abdelazim IA et al. Successful pregnancy outcome immediately after methotrexate treatment for cesarean section scar pregnancy. Gynecol Minim Invasive Ther. 2019;8(4):185-7.

17. Kirk $\mathrm{E}$ et al. Rationalizing the follow-up of pregnancies of unknown location. Hum Reprod. 2007;22(6):1744-50

18. Verhaegen $\mathrm{J}$ et al. Accuracy of single progesterone test to predict early pregnancy outcome in women with pain or bleeding: meta-analysis of cohort studies. BMJ. 2012;345:e6077.

19. Abdelazim IA et al. Relation between single serum progesterone assay and viability of the first trimester pregnancy. J Turk Ger Gynecol Assoc. 2013;14(2):68-71.

20. Doubilet PM, Benson CB. Further evidence against the reliability of the human chorionic gonadotropin discriminatory level. J Ultrasound Med. 2011;30(12):1637-42.

21. Moschos E, Twickler DM. Endometrial thickness predicts intrauterine pregnancy in patients with pregnancy of unknown location. Ultrasound Obstet Gynecol. 2008;32(7):929-34.

22. Crochet JR et al. Does this woman have an ectopic pregnancy? the rational clinical examination systematic review. JAMA. 2013;309(16):1722-9.

23. Hofmann HM et al. Cervical pregnancy: case reports and current concepts in diagnosis and treatment. Arch Gynecol Obstet. 1987;241(1):639.

24. Ge L et al. Ultrasound classification and clinical analysis of ovarian pregnancy: a study of 12 cases. J Gynecol Obstet Hum Reprod 2019;48(9):731-7.

25. Gerli $\mathrm{S}$ et al. Early ultrasonographic diagnosis and laparoscopic treatment of abdominal pregnancy. Eur J Obstet 
Gynecol Reprod Biol. 2004;113(1):1035.

26. Abdelazim IA et al. Primary hepatic pregnancy. J Emerg Trauma Shock. 2019;12(1):68-9.

27. Korhonen $\mathrm{J}$ et al. Serum human chorionic gonadotropin dynamics during spontaneous resolution of ectopic pregnancy. Fertil Steril. 1994;61(4):632-6.

28. Hajenius PJ et al. Interventions for tubal ectopic pregnancy. Cochrane Database Syst Rev. 2007;2007(1):CD000324.

29. Alleyassin A et al. Comparison of success rates in the medica management of ectopic pregnancy with single-dose and multi-dose administration of methotrexate: a prospective, randomized clinical trial. Fertil Steril. 2006;85(6):1661-6.

30. Menon S et al. Establishing a human chorionic gonadotropin cutoff to guide methotrexate treatment of ectopic pregnancy: a systematic review. Fertil Steril. 2007;87(3):481-4.

31. Barnhart KT et al. Use of "2-dose" regimen of methotrexate to treat ectopic pregnancy. Fertil Steril. 2007:87(2):250-6.

32. Gungorduk K et al. Comparison of single-dose and two-dose methotrexate protocols for the treatment of unruptured ectopic pregnancy. J Obstet Gynaecol. 2011;31(4):330-4.

33. Moawad NS et al. Current diagnosis and treatment of interstitial pregnancy. Am J Obstet Gynecol. 2010;202(1):15-29.

34. Hafner T et al. The effectiveness of non-surgical management of early interstitial pregnancy: a report of ten cases and review of the literature. Ultrasound Obstet Gynecol. 1999;13(2):131-6.

35. Weibel HS et al. Multidose methotrexate treatment of cervical pregnancy. J Obstet Gynaecol Can. 2012;34(4):359-62.

36. Jeng CJ et al. Transvaginal ultrasound-guided treatment of cervical pregnancy. Obstet Gynecol. 2007;109(5):1076-82.

37. Hung $\mathrm{TH}$ et al. Prognostic factors for an unsatisfactory primary methotrexate treatment of cervical pregnancy: a quantitative review. Hum Reprod. 1998;13(9):2636-42.

38. Mesogitis S et al. Management of early viable cervical pregnancy. BJOG. 2005;112(4):409-11.

39. Wang $Y$ et al. An efficient conservative treatment modality for cervical pregnancy: angiographic uterine artery embolization followed by immediate curettage. Am J Obstet Gynecol. 2011;204(1):31.e1-7.

40. Di Luigi G et al. Early ovarian pregnancy diagnosed by ultrasound and successfully treated with multidose methotrexate. A case report. Clin Exp Obstet Gynecol. 2012;39(3):390-3

41. Pagidas K, Frishman GN. Nonsurgical management of primary ovarian pregnancy with transvaginal ultrasound-guided local administration of methotrexate. J Minim Invasive Gynecol. 2013;20(2):252-4.

42. Zhang $Q$ et al. Intramural ectopic pregnancy following pelvic adhesion: case report and literature review. Arch Gynecol Obstet. 2019;300(6):1507-20.

43. Bannon $\mathrm{K}$ et al. Diagnosis and management of intramural ectopic pregnancy. J Minim Invasive Gynecol. 2013;20(5):697-700.

44. Ong $\mathrm{C}$ et al. Sonographic diagnosis and successful medical management of an intramural ectopic pregnancy. J Clin Ultrasound. 2010;38(6):320-4.

45. Wang $S$ et al. Intramural ectopic pregnancy: treatment using uterine artery embolization. J Minim Invasive Gynecol. 2013;20(2):241-3.

46. Poole A et al. Early abdominal ectopic pregnancies: a systematic review of the literature. Gynecol Obstet Invest. 2012;74:249-60.

47. Barrenetxea $\mathrm{G}$ et al. Heterotopic pregnancy: two cases and a comparative review. Fertil Steril. 2007:87(2):417.e9-15.

48. Goldstein JS et al. Risk of surgery after use of potassium chloride for treatment of tubal heterotopic pregnancy. Obstet Gynecol. 2006:107(2Pt2):506-8.
49. Soriano D et al. Diagnosis and treatment of heterotopic pregnancy compared with ectopic pregnancy. J Am Assoc Gynecol Laparosc. 2002;9(3):352-8

50. Eom JM et al. Surgical and obstetric outcomes of laparoscopic management for women with heterotopic pregnancy. J Obstet Gynaecol Res. 2013;39(12):1580-6.

51. Kim JW et al. What is the best treatment of heterotopic cervical pregnancies for a successful pregnancy outcome? Clin Exp Reprod Med. 2012;39(4):187-92.

52. Yeh $\mathrm{J}$ et al. Nonsurgical management of heterotopic abdominal pregnancy. Obstet Gynecol. 2013;121(2Pt2Suppl1):489-95.

53. Allison JL et al. Hyperosmolar glucose injection for the treatment of heterotopic ovarian pregnancy. Obstet Gynecol. 2012;12O(2Pt2):44952.

54. Kim SY et al. Cesarean scar pregnancy; diagnosis and management between 2003 and 2015 in a single center. Taiwan J Obstet Gynecol. 2018;57(5):688-91.

55. Mollo A et al. Successful direct bipolar resection of 6 th week cesarean scar pregnancy: case report and literature review. Eur J Obstet Gynecol Reprod Biol. 2014;179:229-31.

56. Mol F et al. Salpingotomy versus salpingectomy in women with tubal pregnancy (ESEP study): an open-label, multicentre, randomised controlled trial. Lancet. 2014;383(9927):1483-89.

57. Siow A, Ng S. Laparoscopic management of 4 cases of recurrent cornual ectopic pregnancy and review of literature. J Minim Invasive Gynecol. 2011;18(3):296-302.

58. Ushakov FB et al. Cervical pregnancy: past and future. Obstet Gynecol Surv. 1997;52(1):45-59.

59. Fernandez $\mathrm{H}$ et al. Fertility after ectopic pregnancy: the DEMETER randomized trial. Hum Reprod. 2013;28(5):1247-53.

60. de Bennetot $M$ et al. Fertility after tubal ectopic pregnancy: results of a population-based study. Fertil Steril. 2012;98(5):1271-6.e3. 